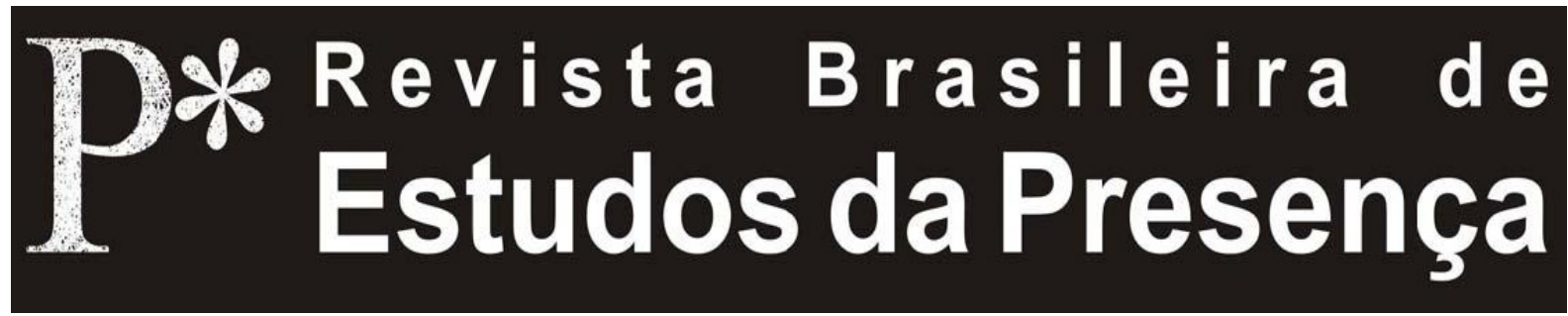

DOI - http://dx.doi.org/10.1590/2237-266039301

ISSN 2237-2660

\title{
Disonancias en la Presencia: el cuerpo y su extensión audiovisual
}

\author{
Isis Saz \\ Universidad de Castilla La Mancha - UCLM, Cuenca, Espanha
}

RESUMEN - Disonancias en la Presencia: el cuerpo y su extensión audiovisual - El presente artículo muestra las consecuencias de la extensión del cuerpo a través del medio audiovisual y cómo esa nueva corporalidad afecta a la percepción del espectador que encuentra una disonancia en la presencia. Lo que entendíamos por cuerpo extiende sus límites a través de la imagen y del sonido y esta capacidad será aprovechada por algunos artistas que basan su trabajo en el cuerpo y que deciden establecerse en ese terreno deslizante entre la presencia corporal y la presencia audiovisual.

Palabras-clave: Cuerpo. Presencia. Audiovisual. Cine. Danza.

ABSTRACT - Dissonances in Presence: the body and its audiovisual extension - This article shows the impact of body extensions through audiovisual language and how this new embodiment affects the perception of the viewer experiencing dissonance in presence. What we previously understood as body expands its limits through images and sounds, and this will be used by some artists who base their work on the body and have decided to work in this fleeting area between physical and audiovisual presence.

Keywords: Body. Presence. Audiovisual. Cinema. Dance.

RÉSUMÉ - Dissonances dans la Présence: le corps et son prolongement audiovisuel - Cet article expose les conséquences du prolongement du corps à travers les techniques audiovisuelles et la façon dont cette nouvelle corporalité touche la perception du spectateur qui découvre une dissonance dans la présence. L'idée de corps se voit étendue dans ses limites à travers l'image et le son et cette capacité particulière sera utilisée par certains artistes qui, fondant leur travail sur le corps, décident de se placer sur ce terrain glissant entre la présence corporelle et la présence audiovisuelle.

Mots-clés: Corps. Présence. Audiovisuel. Cinéma. Danse. 
First it controls your mind, then it destroys your body. VIDEODROME $^{1}$

\section{El Comienzo}

Hace hoy treinta ańos que David Cronenberg estrenaba en pantalla la película Videodrome (1983). En este film de ficción, el vídeo era una nueva arma que traspasaba los límites de lo corporal, trasladando los fenómenos audiovisuales a la realidad y borrando cualquier posible frontera entre el cuerpo matérico y el cuerpo capturado por la cámara. Afortunadamente, en nuestros cuerpos, no se abren ya brechas del tamaño de una cinta de vídeo, fruto de esa simbiosis como ocurriera en el film; sin embargo, es cierto que esa simbiosis de cuerpo y tecnología y la disolución (psicológica) de las fronteras entre la ficción y lo real han marcado y marcan los modos de creación artística en el presente. Aquellas imágenes de James Woods insertando una cinta en su abdomen para adentrarse en una nueva realidad mostraban de forma terrorífica y casi grotesca cual sería nuestra deriva en la relación entre el cuerpo y el medio audiovisual en estos últimos años.

Una característica importante, con respecto al cuerpo real en la imagen, es que muchas de las creaciones actuales se mantienen en esa referencialidad directa del cuerpo. El aspecto real-corporal de la imagen de los cuerpos es un tema común en los últimos años. El vídeo ha cobrado múltiples formas con la aparición de nuevas tecnologías en estos últimos treinta años. Ahora podemos grabar con el teléfono móvil, con la cámara fotográfica, a través de una tableta gráfica o de un dispositivo de webcam. Podemos programar el ordenador para que capture imágenes en un lapso de tiempo y, posteriormente, ver nuestra acción cotidiana enlazada en una secuencia de imágenes aceleradas en el tiempo. La presencia corporal es sustituida por nuestra imagen y sonido cuando hablamos con alguien a través de la webcam. En tiempo real podemos observar la ejecución de una acción que ocurre a miles de kilómetros de distancia. El tiempo se comprime y nuestro cuerpo y nuestra presencia se expanden en el espacio.

Estar en presencia de alguien es reconocer que es nuestro contemporáneo y constatar que se mantiene en la zona de acceso natural de nuestro sentido (aquí, de la vista; en la radio, del oído). Hasta la aparición de la fotografía y del cine, las artes plásticas, sobre todo el retrato, eran los únicos intermediarios posibles entre la presencia concreta y la ausencia. La justificación se centraba en el parecido, que 
excita la imaginación y ayuda a la memoria. Pero la fotografía es distinta. No es ya la imagen de un objeto o de un ser, sino su huella. Su génesis automática la distingue radicalmente de otras formas de reproducción o de registro. Pero la fotografía es una técnica incompleta en la medida que su instantaneidad le obliga a no captar el tiempo que detiene. El cine realiza la extrańa paradoja de amoldarse al tiempo del objeto y de conseguir además la huella de su duración (Bazin, 1958, p. 173).

La noción de presencia tal y como podría ser entendida antes de la aparición de la fotografía, es la que estos nuevos dispositivos de imagen audiovisual modificaron. Primero el cine y, posteriormente, el vídeo, harían que esa interrelación entre el tiempo real y el tiempo grabado se estrechase mucho más, al permitir la retransmisión en directo de las imágenes y no depender de un revelado posterior. Nuestros cuerpos de espectador se acostumbrarían a ese delay de la imagen que se ha trasladado a la imagen digital en la actualidad.

La presencia se define a través de la relación entre tiempo y espacio. Al cambiar estas nociones, se altera a su vez la noción de presencia que, como indica Bazin, tendrá que ser el sentido común el que exprese con mayor claridad y en términos coloquiales cuando queremos referirnos a la presencia corporal de una persona creando la frase "en carne y hueso". Después de más de un siglo observando nuestra huella audiovisual, hemos llegado a un momento en el que la presencia corporal telemática ha sustituido al cuerpo físico en importancia. De ahí el interés porque esa huella sea lo más real posible, para crear una sensación de sustitución en el espectador al otro lado del dispositivo. Las nuevas generaciones se adaptan de forma muy rápida a este nuevo modo de observar y percibir el cuerpo e, inclusive, se puede observar que la propia afirmación de la existencia corporal se basa en su constatación por imágenes grabadas. Nada es real si no ha sido grabado. El cuerpo existe gracias a sus huellas y se interrelaciona con los demás de manera no física. Si bien, se plantean dudas sobre si ese cambio se ha producido por completo hoy en día, o hay algo que todavía escapa e impide hacer efectiva esa simbiosis entre cuerpo físico y cuerpo virtual. Existe una imposibilidad de sustitución que surge por una circunstancia puramente biológica. Si partimos del análisis del funcionamiento de nuestro cuerpo, podemos intuir la razón de que ese reemplazamiento total no sea efectivo, y que paralelamente haya tantas investigaciones en curso para lograr esa fusión de los dos cuerpos en uno. 


\section{Instintivo, Emocional y Racional}

En 1970, Paul McLean desarrolló la teoría del cerebro triple basándose en una propuesta evolucionista. Para McLean, el funcionamiento del cerebro humano se encontraría engranado por tres partes diferenciadas. La primera sería nuestro cerebro primitivo, llamado también cerebro reptiliano. Únicamente permitiría reacciones en tiempo presente, sería el cerebro instintivo que se activaría en situaciones de peligro y que se encargaría de autorregular el organismo en sus funciones básicas. En segundo lugar tendríamos el sistema límbico, donde se gestionarían las emociones y la memoria. Por último, y perteneciente a los mamíferos superiores, se encontraría el neocórtex. Su característica principal residiría en la posibilidad de anticiparse a situaciones futuras. Sería el encargado de la generación o resolución de problemas, análisis y síntesis de información, del uso del razonamiento lógico y del pensamiento crítico y creativo. Cada cerebro o sistema interconectado coordinaría y dirigiría unas determinadas funciones y situaciones corporales (Ledoux, 1999).

De los cinco sentidos que poseemos, no todos estarían controlados por la misma parte de ese sistema cerebral dividido en tres. Las sensaciones visuales y auditivas serían funciones que se asociarían a una predominación del neocórtex. El gusto y el olfato estarían dirigidos por el sistema límbico y, finalmente, el tacto predominaría en el reptiliano.

Aunque la teoría de McLean ha sido revisada estos años, sobre todo en las nuevas investigaciones sobre la inteligencia emocional y nuevos descubrimientos que plantean dudas sobre la ubicación concreta en los órganos internos de estos tres sistemas que propone McLean, nos quedaremos con esta propuesta inicial, sin entrar en el análisis posterior sobre cual sería la localización física concreta de los tres cerebros que se proponía en esta teoría. Lo que nos interesa en este caso es trasladar la propuesta al ámbito artístico en la creación audiovisual en relación a la presencia corporal. En esta nueva era, nuestro funcionamiento diario se basa prácticamente en sistemas basados en la visualidad y la audición generalmente a través de la pantalla de nuestro ordenador. Nuestra condición humana se basta con el sonido y la imagen para hacer suya una realidad alternativa. Puede ser que los otros dos sistemas cerebrales que proponía McLean reclamen sus orígenes animales y adviertan, una y otra vez, que lo 
que estamos percibiendo, no es sino una huella, un residuo, formado por materia que nada tiene que ver con lo orgánico, ya que no podemos sentir nada fuera de la visión o del sonido en esta nueva realidad aséptica. Se han experimentado sistemas de realidad virtual que incorporan olores, sabores y sensaciones táctiles, para lograr una simulación total, pero todavía nos encontramos muy lejos de procurar una sustitución que sea efectiva y engañe a nuestros sistemas del funcionamiento del cerebro más primitivos. Éstos nos devuelven a la materia, al cuerpo vivo, al cuerpo del espectador, dejando atrás el cuerpo inerte y sus huellas, resistiéndose a esa fusión del cuerpo físico con el virtual.

\section{Localizaciones Erróneas}

Henri Bergson ya había intuido la diferenciación de estas escisiones del cerebro y sus implicaciones en el funcionamiento de los mecanismos de percepción. En su libro Materia y Memoria (1896), Bergson apuntaba la diferenciación entre la afección y la percepción y su influencia mutua. Consideraba el cuerpo como centro, que no se limita a reflejar las acciones que se producen sobre éste, sino que en cierto modo absorbe algo de esa acción. Planteaba una metáfora en la que la percepción medía el poder reflector del cuerpo, mientras que la afección medía su poder absorbente.

Mi percepción está siempre fuera de mi cuerpo y mi afección por el contrario está en mi cuerpo. Del mismo modo que los objetos exteriores son percibidos por mí donde están, en ellos y no en mí, mis estados afectivos son sentidos ahí donde se producen, es decir en un punto determinado de mi cuerpo. Consideramos este sistema de imágenes como el mundo material. Mi cuerpo es una de ellas. Alrededor de esta imagen se dispone la representación, es decir su influencia eventual sobre las otras. En ella se produce la afección (Bergson, 2006, p. 69-70).

Para Bergson, no existía una teoría de la percepción pura, ya que ésta siempre estaría condicionada por el cuerpo y su afección. "Nuestro cuerpo no es un punto matemático en el espacio. De ahí que sus acciones virtuales se compliquen e impregnen de acciones reales [...] No existe aquí percepción sin afección” (Bergson, 2006, p. 71).

La simbiosis entre el cuerpo y su imagen audiovisual estaría relacionada directamente con estos conceptos. No existe la imagen pura, ya que ésta va a ser percibida siempre por un cuerpo. Bergson 
habla también de las localizaciones erróneas y pone el ejemplo de la ilusión que tienen algunas personas amputadas, que creen que partes de su cuerpo siguen unidas y hasta tienen sensaciones corporales (mientras que ese cuerpo, ese fragmento ya no está, ha desaparecido).

¿Que concluir de ello, sino que la educación subsiste una vez recibida, y que los datos de la memoria, más útiles en la vida práctica, desplazan los de la conciencia inmediata? Es indispensable, en vista de la acción, traducir nuestras experiencias afectivas en datos posibles de vista, del tacto y del sentido muscular. Una vez establecida esa traducción el original palidece, pero esto no habría podido hacerse jamás si el original no hubiera estado puesto primero, y si la sensación afectiva no hubiera estado (Bergson, 2006, p. 72).

Extrapolamos las ideas de Bergson a la relación entre el cuerpo y su imagen y vemos que existen interesantes paralelismos. Las localizaciones erróneas, fruto de nuestra estructura corporal, serían las que harían posible esa simbiosis entre estos dos cuerpos y su interacción, la confusión o la aceptación de este cuerpo matérico con el cuerpo capturado. Esa aceptación de estos nuevos cuerpos en pantalla podría ser solamente fruto de un error, y se daría únicamente en un instante concreto, en el que el cuerpo es engañado por su percepción.

Nuestra percepción del cuerpo viene dada por múltiples representaciones que de éste observamos, así como de las propiocepciones internas. La observación del cuerpo en los niveles de imagen actuales nos ha procurado un repertorio muy amplio de recursos visuales con los que construir (o re-construir) nuestra propia estructura visible e interna del cuerpo. Si unimos la experiencia visual con un conocimiento amplio de las funciones y movimiento corporales, podemos afirmar que ésta es una de las épocas en las que nuestra autopercepción física del cuerpo puede ser casi completa (si se persigue ese objetivo), lo que da lugar a una visualización combinada de percepciones. Podemos reapropiarnos de nuestra imagen del cuerpo a través de observaciones y capturas del funcionamiento de órganos internos mediante microcámaras, ecografías, radiografías o termografías, hasta recreaciones digitales globales del cuerpo, obtenidas mediante el escaneado de finas láminas de materia ${ }^{2}$, o bien disecaciones de cuerpos para su exhibición ${ }^{3}$. Este nuevo contexto en el que el cuerpo ha sido escrutado al máximo y se combina con estructuras visuales que permiten una nueva visualidad permite que en el ámbito de la creación que se basa en el cuerpo, ya sea arte de acción, danza o tea- 
tro, se haya transformado por completo. También podemos observar que ya no poseemos un cuerpo que pueda estar libre de todos estos condicionamientos. Inclusive estando en el vientre materno, antes de conocer el mundo, nuestra huella del cuerpo ya ha sido capturada mediante ecografías que muestran nuestro primer rastro. Se constata y analiza la presencia de los futuros cuerpos observándola visualmente y sonoramente. Los otros sentidos quedan relegados a un segundo plano, inaugurando una nueva forma de percepción de la presencia.

En base a estos preceptos analizaremos tres obras audiovisuales realizadas por artistas argentinos. Obras que parten de puntos de inicio muy diferentes, pero que tratan de acercarse a esta disonancia que se produce entre la presencia corporal y la presencia audiovisual de los cuerpos.

\section{Disonancias Audiovisuales}

It is hard to tell where you leave off and the camera begins. Minolta. When you are the camera and the camera is you.

Rodrigo Pardo presentó en 2006 la obra Una toma. Un caminar continuo, un gran travelling de cinco minutos que recorre las estancias de un edificio en el que la cámara recoge la imagen de gente trabajando, un bailarín ensayando, una biblioteca, una sala de trabajo... Una mujer con el torso desnudo enlaza las diferentes escenas abriendo el espacio para la ficción, mientras la cámara continúa con su recorrido. En ocasiones se adivina la presencia de los que guían la cámara gracias al reflejo de las estructuras por las que pasan y observamos que también esos reflejos del cuerpo que aparecen en cristales, conduciendo el aparato que registra se encuentran con el torso desnudo. En este punto del recorrido, el cuerpo del espectador se sitúa en el ojo de la cámara. Al final del recorrido, la cámara cambia su sentido y se traslada nuevamente, invirtiendo el sentido del recorrido para volver a las mismas salas. Finalmente, se aleja y el espectador advierte que ha habido un cambio, algo extraño. Esa imagen última que se muestra, es una imagen proyectada en una pared del mismo travelling. Continúa el camino hacia detrás, revelando el truco, el engaño final. Las imágenes de la habitación en la segunda parte del recorrido no eran del mismo lugar, en el mismo tiempo, sino que se trataba de un tiempo diferente, rescatado gracias al audiovisual. Rodrigo Pardo transporta al espectador entre escenas y 
entre estancias con un movimiento de cámara de derecha a izquierda, quizá para recordar que aquello que se experimenta no es algo que avanza al mismo ritmo temporal que el espectador, sino que reproduce algo que ya ha ocurrido antes y que muestra el tiempo pasado. Dos tiempos entrelazados, que se combinan a su vez con esos reflejos de los cuerpos que graba y con los reflejos intuidos y difuminados de los otros dos cuerpos que trasladan la cámara. Cuerpos efímeros que desaparecen, pero que dejan sus huellas. Pensábamos que asistíamos a una escena real, sin cortes, una toma, pero cuando el recorrido finaliza, la ilusión del tiempo vivo se desvanece. Estábamos situados en una zona errónea de percepción.

Deleuze analizaba cómo en las obras de Vertov la relación entre el ojo humano y el ojo de la cámara y la mirada se transformaba en sus creaciones, algo que ocurre de manera similar en esta obra audiovisual.

En Vertov, el intervalo de movimiento es la percepción, el vistazo, el ojo. Pero el ojo no es el del hombre, demasiado inmóvil, sino el ojo de la cámara, es decir, un ojo en la materia, una percepción tal que está en la materia, tal que se extiende desde un punto en que comienza una acción hasta el punto al que llega la reacción, tal que llena el intervalo entre ambos, recorriendo el universo y palpitando a la medida de sus intervalos. La correlación de una materia no humana y un ojo sobrehumano es la dialéctica misma, porque ella es asimismo la identidad de una comunidad de la materia y de un comunismo del hombre (Deleuze, 2005, p. 65).

En la obra audiovisual de Karo Vertical de Fabian Kesler y Gabily Anadon, realizada en el año 2007, nos trasladamos al lado opuesto en esa relación entre el cuerpo y la luz audiovisual. En este caso, el objetivo no es mostrar un cuerpo real en tiempo real, sino hacer visible esa alineación que ha sufrido el cuerpo con el medio audiovisual. Advertimos esa relación entre la luz de los espacios y el cuerpo físico. Los bailarines se interrelacionan con la no materia de lo lumínico, que recorre la escena y la pantalla buscando y encontrando esa materialidad de los cuerpos. Algunos yacen en el suelo, reptan por él; otros permanecen de pie observados por una cámara cenital que describe toda la acción a lo largo de los ocho minutos que dura la grabación. Los cuerpos se adaptan a los rayos lumínicos y éstos los traspasan, como traspasa la luz del escáner un objeto cuando realiza un barrido para captar la imagen. En esta obra, sonido, luz y coreo- 
grafía se unen para lograr una nueva visualidad. Entendemos la no corporeidad gracias a las pausas de sonido, la oscuridad generada en intervalos distantes y la captura o la revelación de esos cuerpos que permanecen latentes en pantalla.

Alejandra Ceriani comenzó en 2005 una serie de experimentaciones con la cámara webcam en su proyecto titulado Webcamdanza. Esta artista explora el cuerpo gracias a este nuevo dispositivo. La intencionalidad pasa por la experimentación con la luz y el registro de fragmentos aislados del cuerpo. Al igual que en Karo Vertical el cuerpo únicamente es visible con el paso de la luz que ilumina la escena. Este proyecto de piezas conecta directamente con las primeras experimentaciones de finales de los años sesenta y principios de los setenta cuando el vídeo irrumpió en la escena contemporánea. En este caso, la curiosidad por la nueva visión del cuerpo se realiza gracias al dispositivo de esa pequeña cámara conectada al ordenador. En la evolución tecnológica del audiovisual y de las cámaras portátiles siempre estuvo presente la inclusión de una pantalla que permitiera visualizar la acción en tiempo real, como si se tratara de un espejo. En los primeros años del vídeo fueron monitores externos a la cámara, posteriormente las pantallas adosadas y giratorias en las cámaras domésticas y fotográficas. Esta artista argentina se ayuda de esta nueva cámara-pantalla para mostrar y observar el movimiento del cuerpo. Jaime Del Val introduce en uno de sus artículos la noción del cuestionamiento de la materialidad de cuerpo, que es posible gracias a la transformación de su representación como consecuencia de los cambios tecnológicos de captura de éste.

La categoría de materialidad (del cuerpo, de la realidad) está intrínsecamente ligada a determinados lenguajes de la cámara y su sedimentación en términos de representación objetiva de la realidad. Transformar radicalmente los lenguajes de la cámara supone transformar el cuerpo y la realidad. Es posible cuestionar la materialidad del cuerpo, transformar su anatomía y su morfología transformando solamente su representación y sus lenguajes (Val, 2006, p. 36).

En la serie acompaña al audiovisual un sonido constante que remite a un escenario acuático, interior. Imaginamos el cuerpo sumergido en las profundidades del abismo marítimo. Las piezas de Alejandra Ceriani del Proyecto Webcamdanza suceden en un mar sonoro de imágenes del cuerpo. Tanto en Karo Vertical como en este 
proyecto, el sonido es fundamental. Podemos decir que el trabajo de audiovisión ${ }^{5}$ que crean estas dos obras abre un nuevo camino para el trabajo con el cuerpo y la imagen en relación al sonido.

Hay una nueva forma de acercamiento a los métodos audiovisuales como forma de trabajar con el cuerpo. Es precisamente esta simbiosis entre cuerpo y vídeo, la que ha dado lugar a algunas de las más audaces e insólitas investigaciones del vídeo experimental. El cuerpo se convierte en soporte y escenario sobre el que va a intervenir la imagen. Las formas en que se realiza esta puesta en imagen de los cuerpos, las maneras de imaginar los cuerpos, constituyen algunas de las mejores aportaciones del vídeo experimental (Pérez Ornia, 1991, p. 76).

El vídeo cobra una importancia relevante como espacio de creación. Las acciones realizadas para la cámara tienen una diferencia fundamental con respecto a las obras pensadas para una presentación ante el público, y es precisamente la presencia de ese público. La cámara ofrece la posibilidad de un proceso más íntimo y es ese espacio el que se expande al máximo. La presencia del público en un escenario provocaría una reacción diferente a la que puede provocar la presencia de la cámara. El cuerpo ya no está sujeto a su exhibición de una forma directa y eso cambia la situación del cuerpo en la acción. Como dice Douglas Davis a propósito de sus obras realizadas en vídeo en directo en los años setenta:

Yo quería documentar otro tipo de realidad, una que se formara y definiera mientras la cámara estaba encendida, no a través de un escenario, o de diálogos o de una narración, sino exclusivamente a través de las imágenes y lo que esas imágenes pudieran sugerir a la mente que las observaba. En otras palabras, descubrir un arte que pudiera verdaderamente existir y ser en el tiempo, el tiempo que ocupaba la cinta y ningún otro (Davis, 2006, p. 95).

Douglas habla de la novedad del vídeo en directo y de esa diferenciación con las obras en presencia de un público:

Lo que realmente me impulsaba - lo que todavía me impulsa - era la emoción de actuar en tiempo real: saber que el momento en el que la cámara se enciende corresponde al momento de grabación o de emisión; experimentar una realidad más intensa, operar a otro nivel. Probablemente es algo bastante indescifrable, porque no estoy hablando simplemente de la emoción de salir al escenario. A lo que me refiero, creo, a lo que Jung se refiere, es a esa intención acentuada hacia las posibilidades del momento que provoca una respuesta psíquica en nosotros en sintonía con el mis- 
mo. De cuando en cuando, de ese proceso salen imágenes que no hubiera podido conseguir ni planeándolo en la sala de montaje. Durante la última década hemos desechado la televisión en directo en busca de la perfección mecánica. Para mi el vídeo en directo representa una forma de trabajar con los sentidos alerta (Davis, 2006, p. 95).

Estamos ante el nacimiento de una nueva forma de pensar a la hora de abordar el trabajo artístico y que tiene mucho que ver con las sensaciones que Douglas Davis describe. La improvisación siempre ha existido en las artes de la escena, pero este tipo de improvisación o de creación instantánea con el cuerpo, la performatividad en estado puro en relación con la imagen es clave para entender muchas de las creaciones actuales. A su vez, el artista ya no está sujeto a un público que lo observa en la ejecución de la acción y esta característica más íntima del vídeo hace posible que el cuerpo se enfrente a la cámara en acciones más sinceras y menos fingidas al no estar sujeto a la interacción con el público, que en ocasiones provoca la asimilación de roles en el cuerpo del artista.

Estos tres ejemplos de obras audiovisuales que se mostraron entre 2005 y 2007 permiten hoy en día fijar las bases sobre cual ha sido la deriva de muchas de las obras realizadas por artistas que trabajan la relación entre el cuerpo y la cámara. En Una Toma asistimos a la visibilización de lo efímero, del tiempo encapsulado que se repite una y otra vez mostrando las huellas de los cuerpos sin cortes ni pausas. En Karo Vertical, el cuerpo alienado, el cuerpo múltiple y el cuerpo escaneado y coreografíado que interactúa con la luz y, por último en Proyecto Webcamdanza, donde asistimos a la audiovisión del cuerpo fragmentado y observado por el ojo de la cámara. Un cuerpo que espera pacientemente esa simbiosis con el cuerpo virtual que no acaba de hacerse realidad. La disonancia en la presencia lo impide. Quizá llegue algún día el momento en el que podamos decir: "Long live to the new flesh"6. 


\section{Notas}

${ }^{1}$ Videodrome. Director: David Cronenberg. 1983.

${ }^{2}$ Uno de los proyectos de investigación más importantes a nivel médico se realizó mediante el escaneado de múltiples cuerpos en láminas horizontales y verticales y posteriormente recompuesto digitalmente. NVIDIA Corporation (Nasdaq: NVDA), crea soluciones de procesamiento visual, como la tecnología NVIDIA Quadro FX 3000 que fue clave para el escaneado de cuerpos 3D y estudios de captura de movimiento para crear a los humanos digitalizados con esqueletos biomecánicos corregidos y músculo, en el documental para Discovery Channel Xtreme Martial Arts.

${ }^{3}$ Ejemplo de ello son las exposiciones sobre el cuerpo que inauguraba el alemán Gunther von Hagens en 1996 (Disponible en: <http://www.bodyworlds.com>. Acceso en: 06 jan. 2009). Otras exposiciones recientes, como Bodies y Erasé una vez... el cuerpo humano, muestran cuerpos y fragmentos de cuerpos momificados mediante la técnica de plastinación. Aún hoy en día estos contenidos son polémicos, y en algunos casos has sido prohibida su exhibición.

${ }^{4}$ Minolta. Anuncio publicitario de 1976.

${ }^{5}$ El concepto de audiovisión remite a que cuando vemos una película, el sonido influye de forma determinante en la manera en la que percibimos las imágenes y las imágenes influyen a su vez en lo que escuchamos. La visión y la escucha se hayan unidos en nuestra percepción, y su interacción hace que percibamos las obras audiovisuales de una forma $\mathrm{u}$ otra (Chión, 1990).

${ }^{6}$ Videodrome, 1983.

\section{Referencias}

BAZIN, André [1958]. ¿Qué es el Cine?. Madrid: Rialp, 2001.

BERGSON, Henri [1896]. Materia y Memoria: ensayo sobre la relación del cuerpo con el espíritu. Buenos Aires: Cactus, 2006.

CHION, Michel. La Audiovisión. Barcelona: Paidós, 1990.

DAVIS, Douglas [1977]. ¡Tiempo! ¡Tiempo! ¡Tiempo! El contexto de la inmediatez. In: Primera Generación. Arte e imagen en movimiento [1963-1986], Madrid, Catálogo del Museo Nacional Centro de Arte Reina Sofía, 2006.

DELEUZE, Gilles [1983]. La Imagen-Movimiento. Estudios sobre cine 1. Barcelona: Paidos, 2005.

LEDOUX, Joseph. El Cerebro Emocional. Madrid: Planeta, 1999.

PÉREZ ORNIA, José Ramón. El Arte del Vídeo: introducción a la historia del vídeo experimental. Barcelona: Serbal RTVE, 1991.

SONTAG, Susan [1973]. Sobre la Fotografía. Madrid: Alianza, 2005.

VAL, Jaime del. Cuerpos Frontera. Imperios y resistencias en el pos-posmodernismo. Organicidades. Artnodes, Barcelona, Universitat Oberta de Catalunya, n. 6, p. 31-43, 2006. 
Isis Saz es doctora en Bellas Artes. Es docente e investigadora de la Universidad de Castilla La Mancha (UCLM), en Cuenca, España. Publicó varios estudios sobre teatro, danza, vídeo y tecnología en la escena contemporánea.

E-mail: isis.saz@uclm.es

Recibido el 24 de abril de 2013

Aceptado para publicación el 02 de junio de 2013 